\title{
Antimicrobial Resistance; The Subtle Killer, in the Mid of Covid-19
}

\author{
Charity Wiafe Akenten* \\ Kumasi Centre for Collaborative Research in Tropical Medicine, Kumasi Ghana \\ *Corresponding author: Charity Wiafe Akenten, Kumasi Centre for Collaborative Research in Tropical Medicine, Kumasi \\ Ghana
}

\section{ARTICLE INFO}

Received: 慧 January 15, 2021

Published: 幽 January 27, 2021

Citation: Charity Wiafe Akenten Antimicrobial Resistance; The Subtle Killer, in the Mid of Covid-19. Biomed J Sci \& Tech Res 33(3)-2021. BJSTR. MS.ID.005399.

Abbreviations: SSA: Sub Saharan Africa; AMR: Antimicrobial Resistance; WHO: World Health Organization

\begin{abstract}
The emergence and spread of COVID-19 around the world have been followed by an increase in antibiotics consumption. This is particularly due to the concern of secondary bacterial infections in COVID-19 patients partly due to the misconception of using antibiotics in treating the disease. The challenge in the situation is that currently in Sub Saharan Africa (SSA), identification and susceptibility of bacterial are uncommon practice in the hospitals. Healthcare providers are unable to effectively discriminate between bacterial and viral infections. Additionally, there remains a strong deliberation on the most effective way of treating COVID-19 infections. Thus, the use of antibiotics employed in COVID-19 patients could drag a second silent pandemic of bacteria resistance of antibiotics. On the other hand, the challenge of COVID-19 has thus increased the awareness and the importance of cleanliness such as hand washing, disinfection, and another equally esteemed hygiene measure that has helped to lessen the spread of antimicrobial-resistant bacteria. Though the above hygiene strategy is important, studies are needed to assess the development of AMR in the era of COVID-19.
\end{abstract}

\section{Opinion}

Antimicrobial resistance (AMR) is no longer a future threat, it is a growing public health concern in every country in the world today which requires a multisectoral action plan. It is estimated that annually, at least 700,000 deaths globally are related to drugresistant infections, a number that may increase to 10 million per year by 2050 - unless significant action is taken [1]. AMR is not only reversing recent gains made in controlling infectious diseases but also undermining improvements in healthcare provision in general. The impacts on disease treatment and deaths will be severe, given that the world is running out of alternative ways to treat AMR infections as people are increasingly taking antibiotics as prophylaxis in this COVID-19 pandemic. This mean that COVID-19 could increase antibiotics resistance, given bacteria's ability to defend themselves against antibiotics. The global COVID-19 pandemic currently has reached a different dimension with an increasing number of critical cases and death. COVID-19 infection is the most severe global health crisis the world has faced in over a hundred years with a maximum attention.

This is because the direct health and economic impact and overall pandemic's implications of COVID-19 for wider populace has been observed dramatically [2]. Wearying the gains of antibiotics in this pandemic era could undermine the role of antibiotics in the medical response to post-COVID-19 era infections. AMR is a health security crisis that moves silently within the community with no known boundaries. The link between COVID-19 and AMR infections is more stressful than we may anticipate. Antibiotics whiles not effective against viruses have been used in people with COVID-19 to prevent or treat suspected secondary bacterial infections without identification of the suspected bacteria [3,4]. A patient with COVID-19 infections is believed to be prone to secondary bacteria as well as fungal infections as may be advocated by the world health Organization (WHO) as such recommends empiric treatment with antibiotics in a high-risk patient. It recommended that proper guidelines need to be adhered to before antibiotics are prescribed.

Though healthcare professionals have been proactive and innovative to slow the spread and lower the transmission rate to protect patients from AMR threats, the situation is still alarming. Active treatment tactics that rely on ground-breaking diagnostics to guide treatment decisions and antibiotic use are needed in the management of COVID-19 patients with suspected secondary 
infections. The predominant use of antibiotics during this pandemic and its management especially in Africa could advance a challenge that the world is already facing in AMR. To best treat patients and minimize AMR in this era of COVID-19, healthcare professionals need to accurately diagnose a patient and know exactly what infections they're up against. As most respiratory infections due to bacterial present many of the same clinical symptoms as COVID-19 patients.

Rapid and Speedy diagnostics can and is a critical element in the management of any outbreak response [5], thus, helping healthcare professionals to better understand patient's infection and guide the apt use of antibiotics will be an addendum to prevent the rise of antibiotic-resistant infections thereby improving antibiotics stewardship.

Incorporation of a routine microbiological strategy for detection of bacteria in respiratory infections should be part of suspected COVID-19 management. As undiagnostic microbial agents could lead to a misdiagnosis, delay inaccurate treatment and the continued spread of possible bacteria in the hospital. Knowing the causative agent of what an infection is not, is just as important as knowing what it is to ensure fast and effective treatment. Health care facilities especially in SSA need access to bacterial rapid diagnostic tests with wider testing skills, beyond focusing exclusively on COVID-19 to know what is causing a patient's symptoms to better enable targeted appropriate antibiotic treatment.

\section{ISSN: 2574-1241}

DOI: 10.26717/BJSTR.2021.33.005399

Charity Wiafe Akenten. Biomed J Sci \& Tech Res

This work is licensed under Creative Commons Attribution 4.0 License

Submission Link: https://biomedres.us/submit-manuscript.php

\section{Conclusion}

AMR one of the WHO global health issues to tackle in 2021, as we know in Africa is a growing health concern in the mid of the COVID-19. The health community must learn the lessons of COVID-19 and take action to fight the silent killer AMR so we will not be caught in surprise for the next potential pandemic of AMR infection.

\section{Conflicts of Interest}

The author declares no conflicts of interest.

\section{References}

1. De Kraker MEA, Stewardson AJ, Harbarth S (2016) Will 10 Million People Die a Year due to Antimicrobial Resistance by 2050? PLoS Medicine 13(11): e1002184.

2. Yaya S, Otu A, Labonté R (2020) Globalisation in the time of COVID-19: Repositioning Africa to meet the immediate and remote challenges. Globalization and Health 16: 51.

3. NIH (2020) Coronavirus Disease 2019 (COVID-19) Treatment Guidelines.

4. Sharifipour E, Shams S, Esmkhani M, Khodadadi J, Fotouhi Ardakani R, et al. (2020) Evaluation of bacterial co-infections of the respiratory tract in COVID-19 patients admitted to ICU. BMC Infectious Diseases 20: 646.

5. Kelly Cirino CD, Nkengasong J, Kettler H, Tongio I, Gay Andrieu F, et al. (2019) Importance of diagnostics in epidemic and pandemic preparedness. BMJ Global Health 4(Suppl 2).

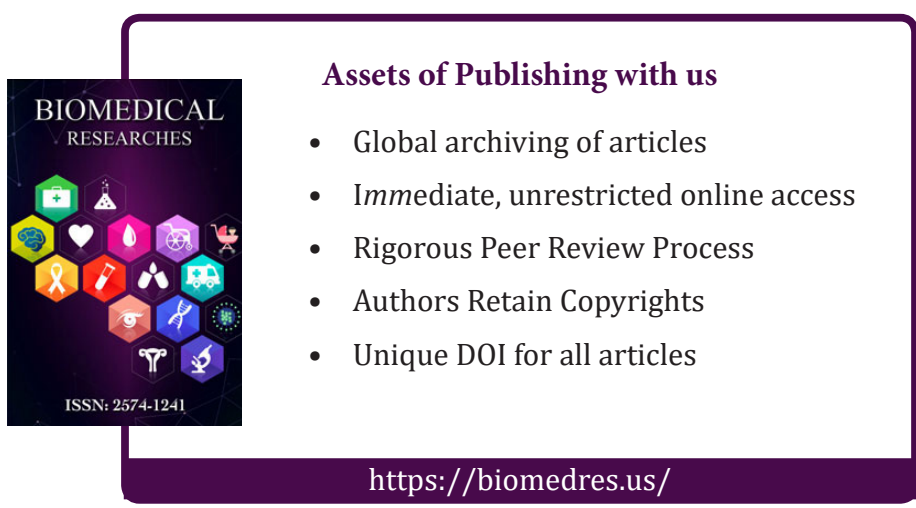

